Check for updates

Cite this: RSC Adv., 2017, 7, 48826

\title{
3D-printed air-blast microfluidic nozzles for preparing calcium alginate microparticles
}

\begin{abstract}
Biao Ye, ${ }^{a}$ Hong Xu, ${ }^{a}$ Binbin Bao, ${ }^{a}$ Jin Xuan ${ }^{b}$ and Li Zhang (D) *a
Microfluidic technologies have emerged as a promising route for precision fabrication of uniform particles. Equipment required for a traditional microfluidic device manufacturing process is expensive and production efficiency is low. It's also difficult to separate a surfactant and continuous phase impurities from particles prepared by a liquid-liquid two-phase shear method. A novel air-blast microfluidic nozzle fabricated using low-cost and efficient 3D printing technology was proposed to prepare calcium alginate particles. Effects of control parameters and solution composition on particle diameters and homogeneity were systematically investigated. Results showed that inlet air pressure has the most significant impact. A nozzle with an outlet diameter of $300 \mu \mathrm{m}$ can produce particles with diameters ranging from $360 \mu \mathrm{m}$ to $2100 \mu \mathrm{m}$. Coefficients of variation (CV) range from $5.3 \%$ to $2.2 \%$. For the same diameter particle prepared, a smaller nozzle outlet had a narrower particle diameter distribution and needed lower inlet air pressure. This method can be used to handle high viscosity solutions and high concentrations of solutions with insoluble solid particles. The prepared particles can be used in biological and pharmaceutical fields.
\end{abstract}

Received 4th August 2017

Accepted 10th October 2017

DOI: 10.1039/c7ra08611c

rsc.li/rsc-advances produce nozzles with an inner diameter of $60 \mu \mathrm{m}$, which could prepare 100-300 $\mu \mathrm{m}$ diameter microparticles for cell cultures; the coefficient of variation (CV) was less than $7.5 \%$ and the roundness of the prepared particles was more than 0.96 . Wang et $a l .{ }^{8}$ embedded a $600 \mu \mathrm{m}$ diameter glass capillary into a square capillary, which could prepare 670-350 $\mu \mathrm{m}$ diameter quaternized chitosan/alginate/ $\mathrm{CaCO}_{3}$ microcapsules where the $\mathrm{CV}$ was less than $5 \%$. However, the glass capillaries need to be tapered and assembled manually, which affects the accuracy and hinders their mass production. ${ }^{\mathbf{9} 10}$ Photolithography and deep reactive ion-etching requires complicated manual operations and has a high cost. ${ }^{11,12}$

3D printing technology, increasingly used in recent years, is more automated and highly repeatable, compared to traditional manufacturing methods, and can print complex structures. ${ }^{\mathbf{1 3 , 1 4}}$ In the last few years, several desktop 3D printers emerging in the market have significantly decreased the cost of $3 \mathrm{D}$ printing. ${ }^{15,16}$ This encouraged researchers to design and develop various 3D-printed microfluidic chips. ${ }^{14-18}$ Comina et al. ${ }^{19}$ used a micro-stereo lithography 3D printer to print a flow channel template. Combined with PDMS pouring technology, they could prepare $50 \mu \mathrm{m}$ to several millimeters chips in 20 minutes. Femmer et al. ${ }^{\mathbf{2 0}}$ used digital light processing (DLP) 3D printers to print a focusing channel microfluidic consisting of 28 parallel channels that could produce $500 \mu \mathrm{m}$ diameter particles and achieve amplification of droplet generation by microfluidic technology. Zhang et al. ${ }^{\mathbf{1 6}}$ used a low-cost Form 1+ printer to create a "plug-and-play" T-type microfluidic device. This device assembled a tubing, a finger tight and a 3D-printed generator
${ }^{a}$ State-Key Laboratory of Chemical Engineering, School of Mechanical and Power Engineering, East China University of Science and Technology, Shanghai, 200237, China

${ }^{b}$ School of Engineering and Physical Sciences, Heriot-Watt University, Edinburgh, EH14 4AS, UK 
together, and could prepare down to $\sim 50 \mu \mathrm{m}$ diameter droplets. Wang et al. ${ }^{21}$ used a fused deposition modelling (FDM) 3D printer (FDM3000) to print an ABS microfluidic chip. Bonyár et al. ${ }^{22}$ fabricated a microfluidic chip for blood sampling with inkjet 3D printing technology and PDMS casting. The use of CAD or Solidworks models gives users the ability to print microfluidics in a just a few hours and at low cost.

Herein, we propose a 3D-printed air-blast microfluidic nozzle for generating monodisperse droplets. The nozzle is printed using a desktop DLP 3D printer. In addition, the effects of the nozzle diameter, solution concentration, gas and liquid flow rate on the preparation of droplets were also studied. Our calcium alginate microparticles containing solid $\mathrm{CaCO}_{3}$ particles were prepared with this nozzle.

\section{Materials and methods}

\subsection{Design and printing of the nozzle}

A novel microfluidic nozzle was designed using Solidworks software and printed using DLP methodology. Fig. 1 exhibits the 3D-printed microfluidic nozzle structure diagram. The nozzle is mainly composed of a dispersed phase channel and continuous phase channel which are designed coaxially as shown in Fig. 1a. The dispersed phase liquid passes through an intermediate channel and the continuous phase gas passes through the circular annulus channel. At the outlet, gas produces a shearing action on the liquid, causing the formation of droplets. So, the droplet diameter can be precisely controlled by adjusting the flow rate of the gas.

The dispersed phase channel inlet is directly connected to the Teflon tube, so the inlet diameter is designed according to the Teflon tube fitting (Fig. 1a). The inner diameter of the dispersed phase channel is $2 \mathrm{~mm}$, the outer diameter is $5 \mathrm{~mm}$, and the total length of the liquid flow channel is $27.5 \mathrm{~mm}$. The continuous phase inlet diameter is $3 \mathrm{~mm}$. In order to facilitate the direct insertion of the trachea and ensure no leakage, the

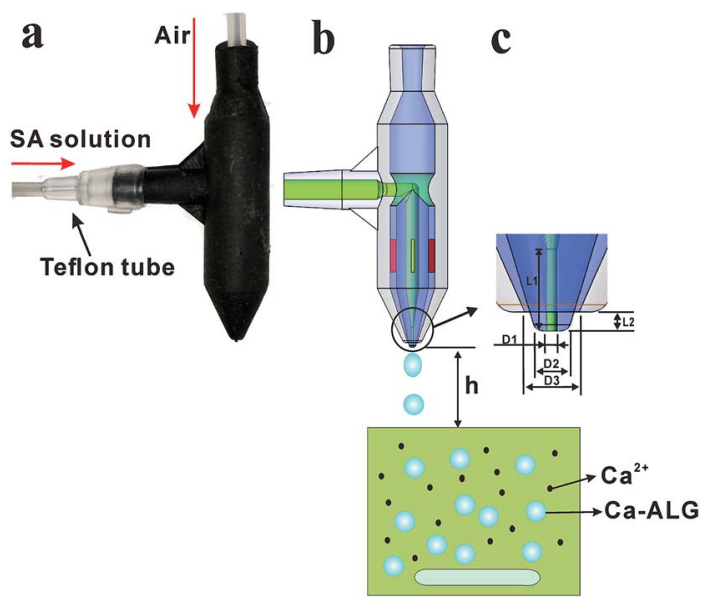

Fig. 1 Schematic diagram of the air-blast nozzle for calcium alginate microparticle preparation: (a) physical drawing; (b) schematic diagram of the preparation; and (c) outlet magnification. inlet has a certain taper. The inner diameter of the continuous phase channel is $7 \mathrm{~mm}$ and the outer diameter of it is $10 \mathrm{~mm}$. In order to improve the strength of the T-junction, we designed two symmetrical ribs of $2 \mathrm{~mm}$ thickness. According to Fig. 1b, the dispersed phase channel runs directly through the continuous phase channel at the T-junction; this design ensures the gas flows symmetrically from both sides and maintains a uniform distribution of it.

Due to the inherent properties of the 3D printing resin, the printed product will slightly deform after a few days. So, four symmetrical ribs (red part) were added between the two channels as shown in Fig. 1b. These four ribs guarantee a continuous phase channel and dispersed phase channel that are coaxial. In order to minimize the influence of the ribs to the air flow field, the width of them is only $0.5 \mathrm{~mm}$.

Although the resolution of the current desktop printer can reach to $30 \mu \mathrm{m}$, the actual printed channel diameter is only $250 \mu \mathrm{m}$. During the printing process the uncured resin in the small channel is difficult to remove, so the printed channel cannot be long or complex. ${ }^{23}$ In order to have low cost and high stability, in this paper the smallest diameter channel was printed about $300 \mu \mathrm{m}$. The largest diameter of particles produced by $500 \mu \mathrm{m}$ outlet nozzles can reach to $2575 \mu \mathrm{m}$, which is large enough for the microfluidics field. ${ }^{7,8}$ Therefore, $500 \mu \mathrm{m}$ was selected as the largest outlet diameter for printed nozzles. The structure of a slender hole is difficult to print. The channels (Fig. 1c) are designed according to the parameters in Table 1. This design avoids excessive slender holes structures in the nozzle, making it easier to print.

A larger drag force will be favorable for making smaller droplets. The drag force can be computed as:

$$
F_{\mathrm{D}}=0.5 C_{\mathrm{D}} A u^{2} \rho .
$$

where $u$ and $\rho$ are the velocity and density of the flowing liquid, respectively, $C_{\mathrm{D}}$ is the drag coefficient, and $A$ is the crosssectional area of the obstacle..$^{24,25}$ If the gas flow is certain, a smaller $D_{2}$ and $D_{3}$ could reduce the cross-sectional area of the annular gas flow channel and increase the velocity of gas, which is favorable for making smaller droplets. But, it's difficult for the DLP 3D printer to print a wall or clearance smaller than $300 \mu \mathrm{m}$. The $D_{2}$ and $D_{1}$ were designed by the minimal size of $300 \mu \mathrm{m} . L_{2}$ was designed as $1 \mathrm{~mm}$ by Ikki Horiguchi et al. ${ }^{26}$ And for our nozzles, $0.7 \mathrm{~mm}$ is also suitable after being tested many times. Importantly, the small $L_{1}$ and $L_{2}$ could reduce the length of the liquid channel and reduce the risk of channel blockages by the resin during the process of $3 \mathrm{D}$ printing.

Table 1 Different nozzles used in the experiment

\begin{tabular}{lccc}
\hline Nozzle parameters & $\mathrm{N}_{300}$ & $\mathrm{~N}_{400}$ & $\mathrm{~N}_{500}$ \\
\hline$D_{1}(\mathrm{~mm})$ & 0.3 & 0.4 & 0.5 \\
$D_{2}(\mathrm{~mm})$ & 0.9 & 1.0 & 1.1 \\
$D_{3}(\mathrm{~mm})$ & 1.5 & 1.6 & 1.7 \\
$L_{1}(\mathrm{~mm})$ & 3.0 & 3.0 & 3.0 \\
$L_{2}(\mathrm{~mm})$ & 0.7 & 0.7 & 0.7
\end{tabular}


The nozzles were printed with a low-cost desktop printer, B9Creator (B9 Creations, Inc.). The B9Creator is a DLP printer and the maximum printing volume is $104 \mathrm{~mm} \times 75.6 \mathrm{~mm} \times$ $203.2 \mathrm{~mm}$. DLP is similar to stereolithography; the major difference is the light source. DLP uses a more conventional light source with a deformable mirror device (DMD), which is applied to the entire surface of the vat of photopolymer resin in a single pass, generally making it faster than SL which traces the outline of every part on every pass. One major advantage of DLP is high feature resolution, provided by the process of photocuring a resin with a UV laser, making it possible to print a smaller hole and stick. ${ }^{13}$ So, DLP gradually became popular for fabricating droplet-based microfluidic devices since a smooth channel surface is crucial for droplet creation and transportation inside the microchannels. Another benefit of DLP is the diversity of different resins, such as pic100, B9R-CHERRY, B9R-BLACK, B9R-RED, and clear resin. This photo-sensitive resin consists of a modified acrylate oligomer, monomer, and a photoinitiator, but their weight ratio is proprietary. The BLACK resin (Shanghai EETEX Chemical Technology Co., Ltd.) provided the highest precision, so it was used during the experiments.

After printing, the nozzle was immediately put into alcohol and ultrasonically rinsed for 2 minutes, and then a syringe was used to extract alcohol and flush the nozzle internal channels. Finally, the nozzle was ultrasonically rinsed for another 5 minutes to remove the uncured resin.

\subsection{Preparation process for calcium alginate microparticles}

Fig. $1 \mathrm{~b}$ is the schematic diagram for preparing calcium alginate particles by the 3D-printed air-blast microfluidic nozzle. In the experiment, a constant pressure pump (WH-PMPP15) was used to adjust the air pressure generated by the air compressor. Between the nozzle and air compressor a rotor flow meter was connected to measure the air flow rate. The constant pressure pump guarantees the gas flow rate and controls the diameter of the droplets; the precision is up to $0.001 \mathrm{MPa}$. Single-channel syringe pumps (Longer LSP01-1A) were used to pump the dispersed phase sodium alginate (SA) solution. The pump was connected to the nozzle with Teflon tubes and droplets were dropped directly into a beaker containing $\mathrm{CaCl}_{2}$ solution and stirred at a rate of $120 \mathrm{rpm}$.

Different concentrations of sodium alginate solution (SigmaAldrich) were used as the dispersed phase. Alginate is a linear copolymer composed of $\alpha$-L-guluronic acid and $\beta$-D-mannuronic acid, and is easily transformed into an 'egg box' type hydrogel with multivalent cations such as $\mathrm{Ca}^{2+}$. When the required drug is added to a sodium alginate solution, it can be packed together to form a capsule of a specific function. In this experiment, the SA powder was dissolved in a water bath at $60{ }^{\circ} \mathrm{C}$, cooled to room temperature, and then dropped into a $15 \mathrm{wt} \%$ $\mathrm{CaCl}_{2}$ solution through a nozzle to produce solid particles. In order to simulate the effect of insoluble drug loading, $\mathrm{CaCO}_{3}$ microparticles (Sinopharm Chemical Reagent Co. Ltd.) with diameters of 48-75 $\mu \mathrm{m}$ were used as an additive in the experiment.

\subsection{Measurements of microparticles}

After sufficient reaction and solidification, the solid particles in $\mathrm{CaCl}_{2}$ solution were filtered out under vacuum. Their diameters were measured when they were wet. The microparticles were observed with an optical microscope (OLYMPUS SZX7) and their sizes were analyzed using the free image-analysis software Image-ProPlus. All experiments were carried out at room temperature. Particle monodispersity was defined using coefficients of variation (CV) ${ }^{27-29}$ according to formulas (1) and (2) and 300 particles were measured each time in this experiment. Lower CV values indicate narrower (better) microsphere size distributions. SEM (JEOL JSM-6380LV) was also employed to observe more detailed structures of the particles. The particles were freeze-dried and then cut with a blade to observe their internal morphology. For easy cutting, wet particles of about $2 \mathrm{~mm}$ were selected.

$$
\begin{gathered}
\overline{D_{n}}=\sum_{i=1}^{n} \frac{d_{i}}{n} \\
\mathrm{CV}=\frac{\left(\sum_{i=1}^{N} \frac{\left(D_{i}-\overline{D_{n}}\right)^{2}}{(N-1)}\right)^{\frac{1}{2}}}{\overline{D_{n}}} \times 100 \%
\end{gathered}
$$

\section{Results}

\subsection{Effect of microfluidic control parameters on particles}

3.1.1 Effect of distance from nozzle outlet to liquid surface. In the process of microparticle preparation, the particle shape affects the particle properties. Wang et al. ${ }^{\mathbf{3 0 , 3 1}}$ found that the outlet height $h$ affected the shape of the particles by the coflowing streams method. In order to study the effect of the outlet height $h$ on the microparticles, conditions of the experiment are listed as follows: flow rate $Q=400 \mu \mathrm{L} \mathrm{min}{ }^{-1}$, inlet pressure $P=40 \mathrm{kPa}$, nozzle diameter $D_{1}=300 \mu \mathrm{m}$. Microparticles with different $h$ were prepared and observed with an optical microscope.

Fig. 2 shows the effect of the distance $h$ on the particles shape. When the distance $h$ is more than $40 \mathrm{~mm}$ (Fig. 2(a) and (b)), the microparticles have a good spherical shape with almost no oval particles; they were uniform like the gelatin particles prepared by Marcel Workamp's ${ }^{25}$ nozzle. When the distance $h$ decreased to $20 \mathrm{~mm}$, some oval particles appeared, as shown in Fig. 2(c) and (d). When $h$ continues to decrease, the number of oval particles will increase. Under each experimental condition, we selected about 300 particles to estimate percentage of the non-spherical particles, and the percentages of non-spherical particles in the four graphs from (a) to (d) were $2.1 \%, 4.2 \%$, $8.3 \%$, and $18.6 \%$, respectively. When the droplets left the exit, they were ovals as shown in Fig. 1b. During the process of falling, droplets shrink into a spherical shape due to surface tension, which needs a distance to occur. If $h$ is too low, the droplet does not have enough distance and time to shrink into a ball, and particle sphericity is decreased. Furthermore, the airflow which blows to the liquid surface and then bounces back 

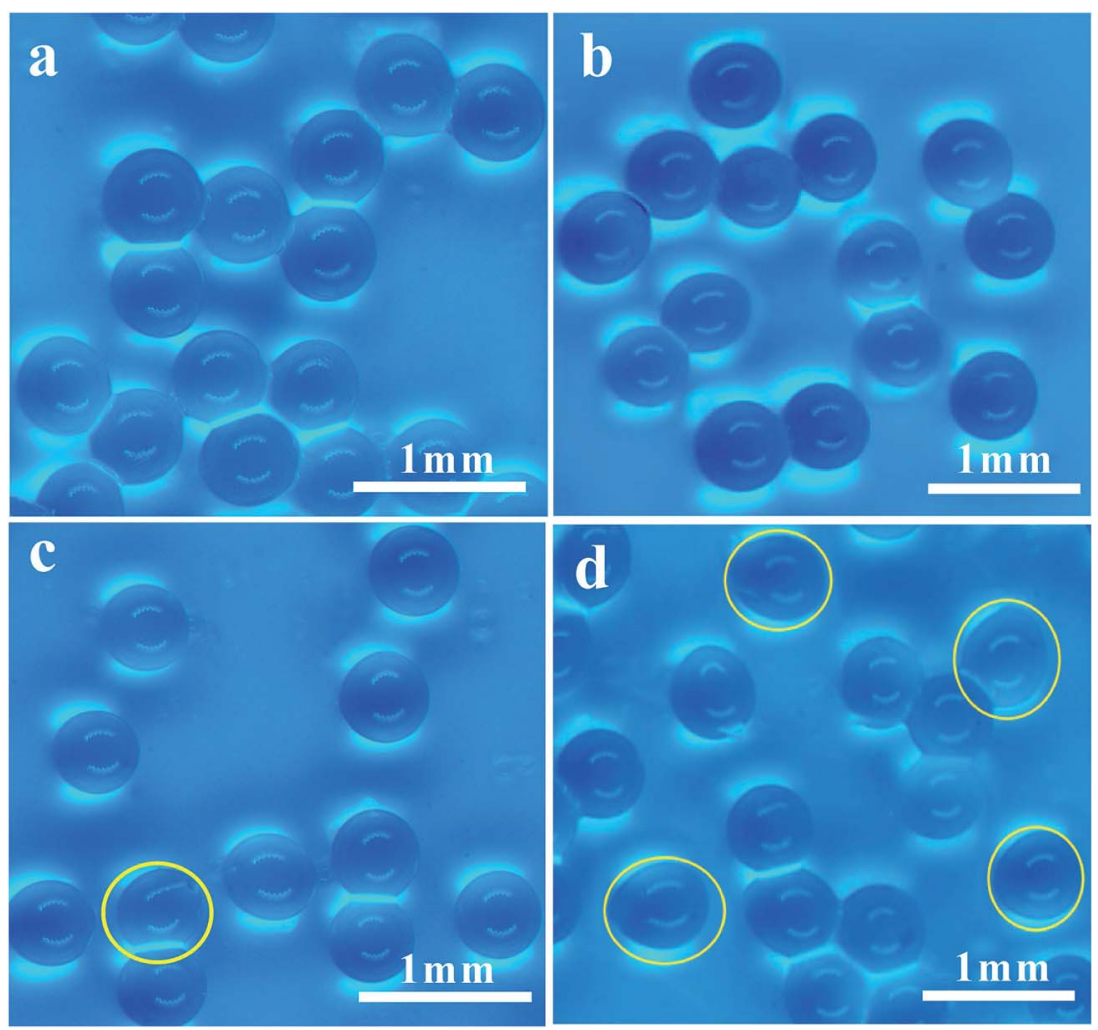

Fig. 2 Optical photograph of the microparticles: (a) $1.5 \mathrm{wt} \% \mathrm{SA}, h=40 \mathrm{~mm}$; (b) $2 \mathrm{wt} \% \mathrm{SA}, h=40 \mathrm{~mm}$; (c) $1.5 \mathrm{wt} \% \mathrm{SA}, h=20 \mathrm{~mm}$; and (d) $2 \mathrm{wt} \%$ $\mathrm{SA}, h=20 \mathrm{~mm}$.

to the nozzle will also influence the outlet flow field, resulting in changes to the shape of the droplets.

Comparing Fig. 2(c) with Fig. 2(d), when the solution concentration increased from $1.5 \mathrm{wt} \%$ to $2 \mathrm{wt} \%$, the sphericity of the particles was significantly decreased at the outlet distance $h$ of $20 \mathrm{~mm}$. The SA solution concentration and the viscosity was higher and the time required for the droplets to shrink into a ball was longer, so the sphericity was significantly decreased. According to experimental results, when the concentration of sodium alginate is less than $2 \mathrm{wt} \%$ and distance $h$ is more than $40 \mathrm{~mm}$, then better spherical particles can be achieved. When the solution concentration increases, the required distance also increases. In order to gain spherical particles, the distance $h$ should be kept above $40 \mathrm{~mm}$.

3.1.2 Effect of inlet gas pressure. Fig. 3 shows the prepared particle diameters and $\mathrm{CV}$ values under different inlet pressures from three nozzles with different outlet diameters. It can be seen that the inlet pressure has significant effect on particle size. In the experiment, the liquid phase flow rate $Q=200 \mu \mathrm{L} \mathrm{min}{ }^{-1}$, the SA solution concentration is $1.5 \mathrm{wt} \%$, and the distance $h=$ $40 \mathrm{~mm}$. As the inlet gas pressure increased from 0 to $90 \mathrm{kPa}$, the prepared particles also regularly decreased. The particle diameter prepared by a $500 \mu \mathrm{m}$ diameter nozzle decreased from $2575 \mu \mathrm{m}$ to $436 \mu \mathrm{m}$ and the particle $\mathrm{CV}$ value increased from $2.79 \%$ to $5.34 \%$. For the $300 \mu \mathrm{m}$ diameter nozzle, the particle diameters ranged from $2100 \mu \mathrm{m}$ to $380 \mu \mathrm{m}$, and the $\mathrm{CV}$ increased from $2.22 \%$ to $5.32 \%$ and had a wider particle diameter range compared with the range from 670 to $350 \mu \mathrm{m}$. $^{8}$
Changing the nozzle inlet gas pressure can lead to changes of gas flow rate at the outlet and the shear action of the continuous phase to dispersed phase, thus resulting in a change of the size of the droplet at the outlet. Before the droplet dripping, the surface tension makes them shrink into a ball and suspend at the outlet. Gravity and shear force promote droplets to drip, which has the opposite effect of surface tension.

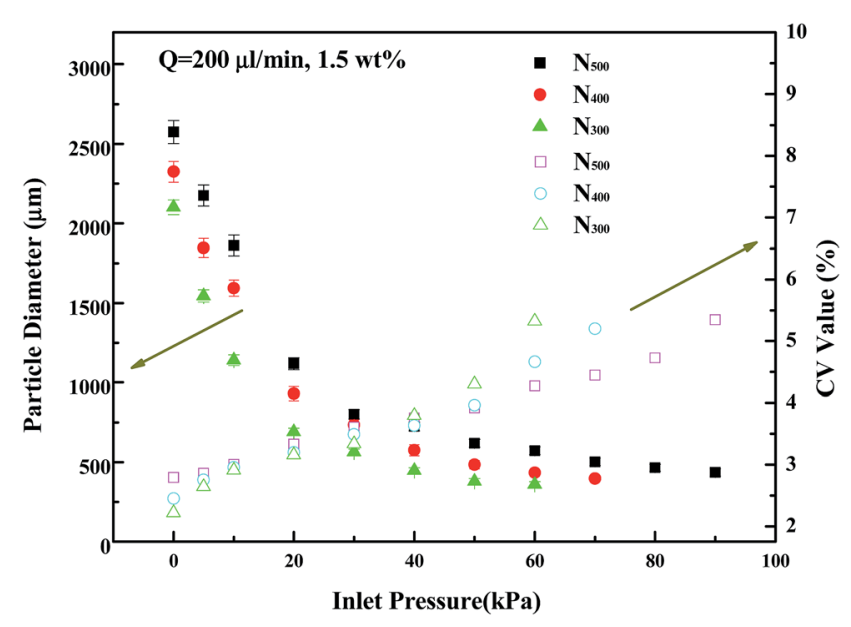

Fig. $3 \mathrm{CV}$ values and particle diameters prepared under different inlet pressures from 300,400 , and $500 \mu \mathrm{m}$ outlet nozzles, respectively $(Q=$

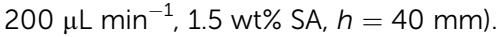


With increasing gas velocity, the shear effect of gas to droplet also increased, causing the droplets drip early, so the droplet diameters decreased. When the gas pressure is less than $30 \mathrm{kPa}$, the pressure regulation effect is obvious and particle size decreases quickly. When the air pressure is higher than $30 \mathrm{kPa}$, a larger gas pressure increment is needed to reduce the same particle diameter. When the inlet gas pressure is low, the droplets are big and have large surface areas, so a small pressure change can provide large shear force change. When the inlet gas pressure continues to increase, droplets are easily broken by the shear force and form additional smaller droplets; then the $\mathrm{CV}$ value will rise rapidly. So, in our experiments we only considered conditions about $\mathrm{CV} \sim 5 \%$.

3.1.3 Effect of liquid flow rate. Fig. 4 shows the effect of liquid flow rate on particle diameters. From Fig. $4 \mathrm{a}$ it is seen that when inlet air pressure is constant, increasing the liquid flow rate has little influence on particle size and particle diameters

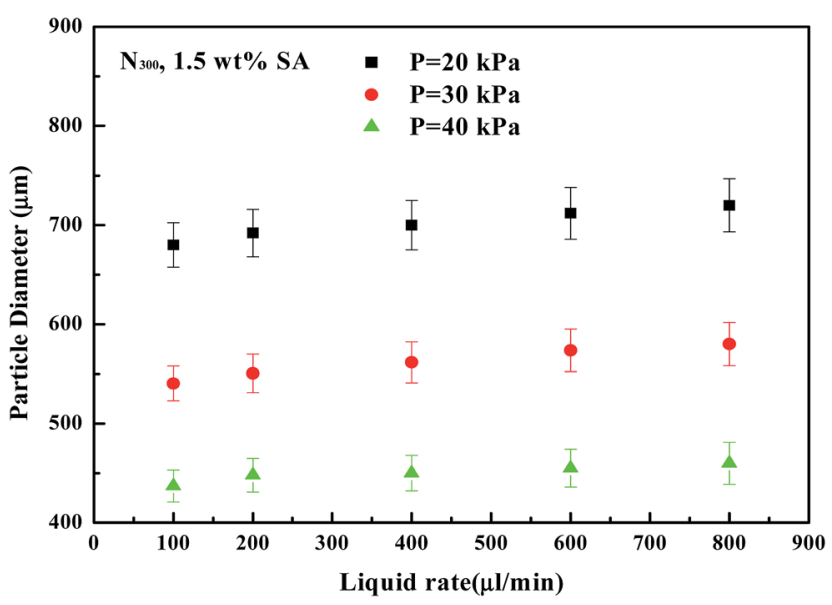

(a)

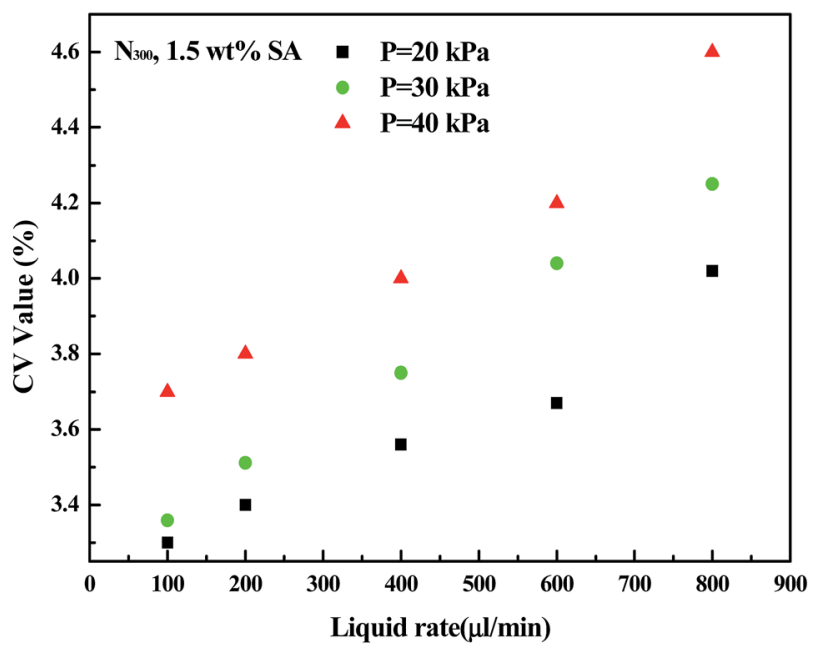

(b)

Fig. 4 (a) Effect of liquid flow rate on particle diameter. (b) Effect of liquid flow rate on particle $\mathrm{CV}$ value $\left(1.5 \mathrm{wt} \% \mathrm{SA}, h=40 \mathrm{~mm}, \mathrm{~N}_{300}, P=\right.$ 20,30 , and $40 \mathrm{kPa}$ ). increase slightly. In the experiment, the distance $h$ of the outlet to liquid surface was $40 \mathrm{~mm}$ and the concentration of sodium alginate was $1.5 \mathrm{wt} \%$. At an inlet gas pressure of $30 \mathrm{kPa}$, when the liquid flow rate increased from $100 \mu \mathrm{L} \mathrm{min}{ }^{-1}$ to $800 \mu \mathrm{L} \mathrm{min}{ }^{-1}$, the particle diameter only increased from $540 \mu \mathrm{m}$ to $580 \mu \mathrm{m}$. The shear force between gas and liquid is proportional to the velocity gradient and the velocity gradient can be simply approximated by the relative velocity difference between gas and liquid. In this experiment, the gas flow rate was between $0.5 \mathrm{~L} \mathrm{~min}^{-1}$ and $4.33 \mathrm{~L} \min ^{-1}$, and the maximum liquid velocity was

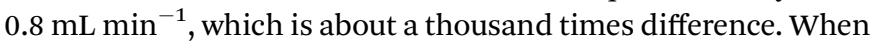
the liquid flow rate increases, the relative velocity decreases slightly, so the particle diameter change is not obvious.

As can be seen from Fig. 4b, when the liquid flow increased, the $\mathrm{CV}$ value of the particles increased significantly. Liquids at the nozzle outlet gathered into small droplets, and it takes some time to drip. If the liquid flow rate is high, the time needed is short and the distance between two droplets is short and the interference between two droplets increases. The droplets have not enough time to shrink into a ball shape before they fall off, so $\mathrm{CV}$ values increase. When the flow rate is $600 \mu \mathrm{L} \mathrm{min}^{-1}$, the distance between the droplets is very short and droplets quickly are generated at the outlet. When the flow rate reaches $800 \mu \mathrm{L} \mathrm{min}^{-1}$, the liquid at the outlet nearly becomes a line. So, when the flow rate is more than $600 \mu \mathrm{L} \mathrm{min}{ }^{-1}$, then $\mathrm{CV}$ values of the particles increase significantly.

3.1.4 Effect of nozzle outlet diameter. The nozzle outlet diameter has an important influence on the preparation of functional particles. Here we studied liquid outlets of $300 \mu \mathrm{m}$, $400 \mu \mathrm{m}$, and $500 \mu \mathrm{m}$ diameters. In this experiment, liquid flow rate was appropriately $200 \mu \mathrm{L} \mathrm{min}{ }^{-1}$, the outlet distance $h=40 \mathrm{~mm}$, and concentration of sodium alginate was $1.5 \mathrm{wt} \%$.

Fig. 5 shows the diameters and $\mathrm{CV}$ values of particles prepared by different outlet diameter nozzles. By changing the inlet air pressure, particles with different diameters were obtained. As shown in the figure, when preparing the same

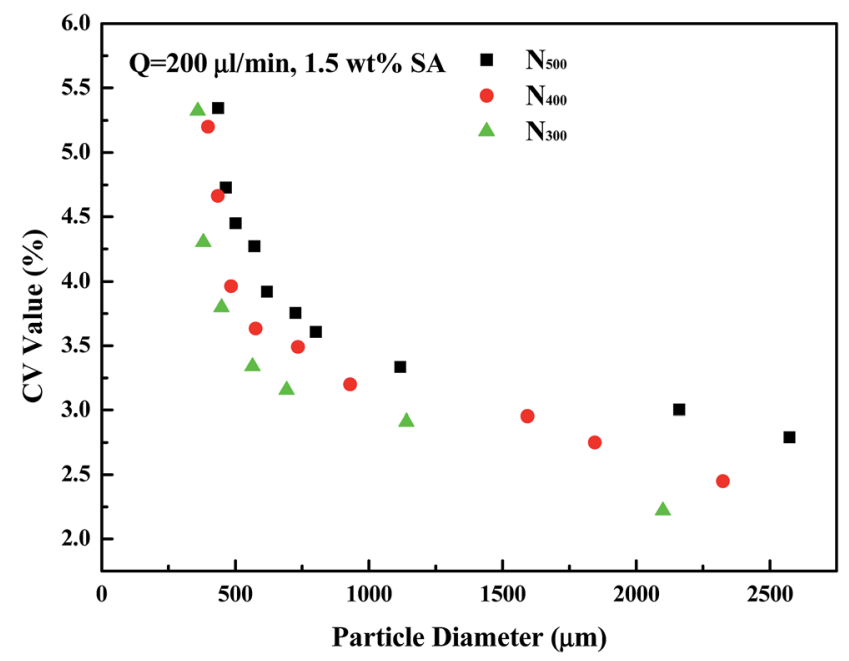

Fig. 5 Diameters and CV values of particles prepared by $N_{300}, N_{400}$, and $\mathrm{N}_{500}$ nozzles, respectively $\left(Q=200 \mu \mathrm{L} \mathrm{min}^{-1}, h=40 \mathrm{~mm}, 1.5 \mathrm{wt} \%\right.$ $\mathrm{SA})$. 
diameter particles, a larger outlet diameter nozzle has larger CV values, and the $\mathrm{CV}$ values of the $300 \mu \mathrm{m}$ nozzle are the smallest. The larger the nozzle outlet diameter is, the larger the maximum particle diameter is. Combined with Fig. 3, at the same particle diameter, the smaller nozzle outlet needed lower gas flow rate. This not only saves gas energy, but also maintains experimental stability. $300 \mu \mathrm{m}, 400 \mu \mathrm{m}$, and $500 \mu \mathrm{m}$ nozzles can produce the smallest droplets: about $360 \mu \mathrm{m}, 397 \mu \mathrm{m}$, and 436 $\mu \mathrm{m}$, respectively. If the inlet air pressure continues to increase, particle diameter change is not obvious, but CV values significantly increase.

The smaller diameter outlet nozzle has a smaller crosssectional area of the liquid at the outlet, and the intermolecular viscous force is small, so the fluid is easier to be cut off by the gas. Therefore, in a follow-up study, in order to get smaller particles, we will try to print channels with smaller diameters.

\subsection{Effect of solution composition}

3.2.1 Effect of sodium alginate solution concentration. Fig. 6 shows the effect of sodium alginate solution concentration on particle diameters. In the experiment, the inlet gas pressure was about $30 \mathrm{kPa}, 40 \mathrm{kPa}$, and $50 \mathrm{kPa}$, and liquid flow

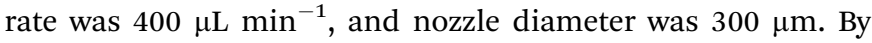
changing the liquid concentration, particle diameter distribution is obtained. From Fig. 6(a), the particle diameter increases substantially linearly as the liquid concentration increased. When the concentration of sodium alginate is more than $1.5 \mathrm{wt} \%$, the particle diameter increases obviously. The viscosity of the sodium alginate solution increased exponentially when the solution concentration increased. The increase in viscosity leads to an increase in surface tension. At the same gas shear force, more gravity is required to cause the droplet to fall off, resulting in a bigger droplet diameter.

According to Fig. 6(b), with an increase in sodium alginate solution concentration, the particle distribution is more nonuniform. When the solution viscosity increases, it is more difficult to separate the droplets by shear force. The minimum internal channel diameter of the nozzles is $2 \mathrm{~mm}$, and the total length of the channel is $27.5 \mathrm{~mm}$. Compared to the slender structure of a traditional microfluidic chip, ours has minor resistance, so it can prepare droplets with larger viscosity.

Change of solute concentration in the liquid solution will change the viscosity and density of it, which then affects size and shape of the microparticles. A higher concentration of sodium alginate solution can produce higher strength and better elastic hydrogel particles, ${ }^{32}$ which is why some scholars are hoping to improve the concentration of sodium alginate solution. However, the sodium alginate solution is a nonNewtonian fluid with shear thinning. When the concentration is greater than $1.5 \mathrm{wt} \%$, the growth rate becomes significantly faster. ${ }^{33}$ A liquid-liquid shear method is usually used to prepare sodium alginate at a concentration of less than $2 \mathrm{wt} \%$. If the solution concentration is too high, the continuous phase flow rate should be tens of times higher than before. This requires a high cost of continuous phase material, and even then, it is not able to successfully generate particles.

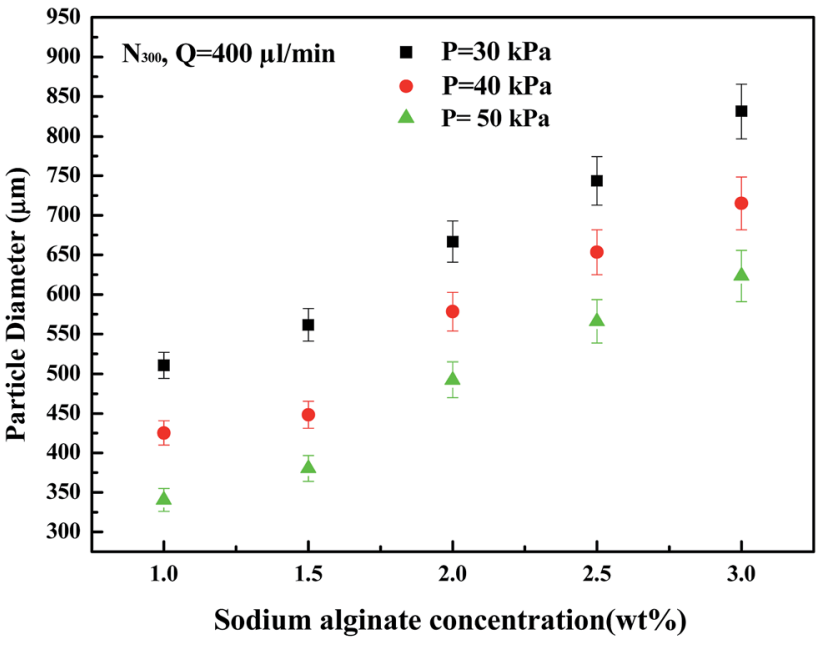

(a)

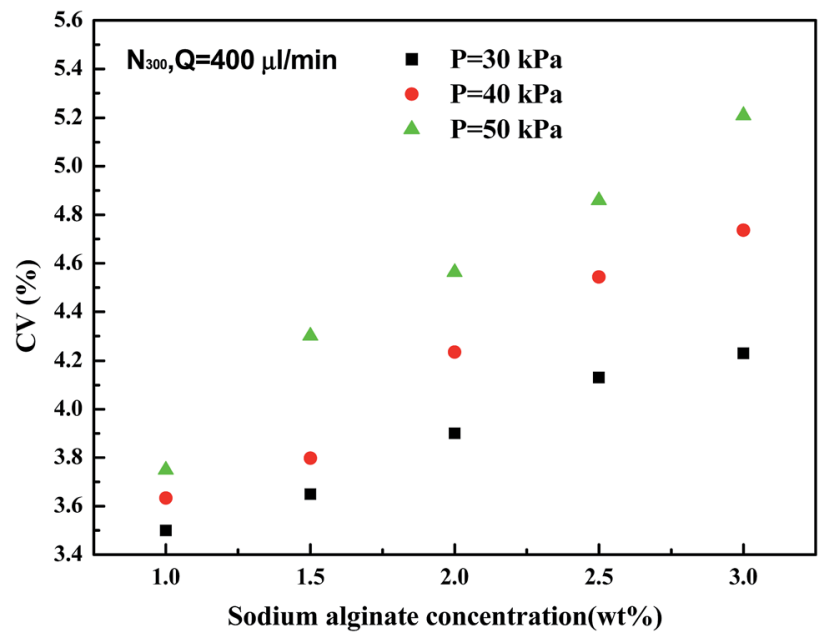

(b)

Fig. 6 (a) Effect of sodium alginate solution concentration on particle diameter. (b) Effect of sodium alginate solution concentration on particle $C V$ value $\left(Q=400 \mu \mathrm{L} \min ^{-1}, h=40 \mathrm{~mm}, \mathrm{~N}_{300}, P=30,40\right.$, and $50 \mathrm{kPa})$.

3.2.2 Effect of adding solid particles. $\mathrm{CaCO}_{3}$ is insoluble in sodium alginate solution. Therefore, a sticky suspension will form after adding $\mathrm{CaCO}_{3}$ to sodium alginate solution. $\mathrm{A} \mathrm{CaCO}_{3}$ sodium alginate solution has higher viscosity, poorer mobility, and is easier to plug microfluidic devices. In the fields of genetic engineering, biology, and medicine, it is often necessary to prepare sodium alginate functional granules containing $\mathrm{CaCO}_{3}$ or similar insoluble drugs for special uses such as making porous materials. ${ }^{34,35}$

The 3D printing microfluidic nozzle in this paper has a $300 \mu \mathrm{m}$ diameter outlet with length of only $3 \mathrm{~mm}$, so it will not be blocked in the experiments. As shown in Fig. 7, at an inlet gas pressure of $20 \mathrm{kPa}, 5 \mathrm{wt} \%, 10 \mathrm{wt} \%$, and $15 \mathrm{wt} \%$ $\mathrm{CaCO}_{3}$ powder with diameters of $48-75 \mu \mathrm{m}$ were directly added into $1.5 \mathrm{wt} \%$ sodium alginate solution to prepare composite microparticles. The obtained particles have 

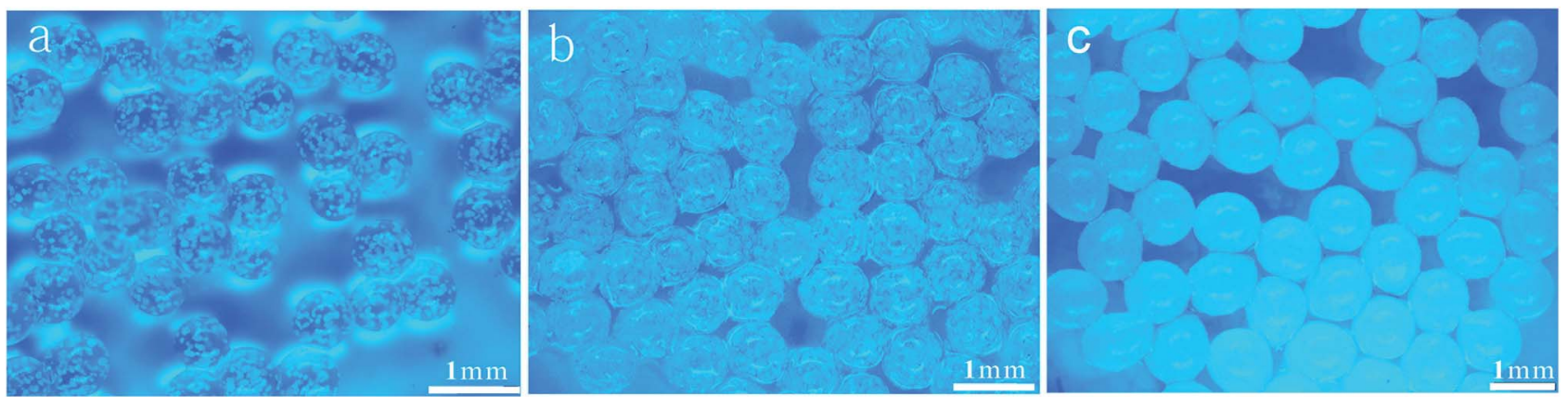

Fig. $7 \mathrm{CaCO}_{3}$ calcium alginate particles. (a) $5 \mathrm{wt} \% \mathrm{CaCO}_{3}$; (b) $10 \mathrm{wt} \% \mathrm{CaCO}_{3}$; and (c) $15 \mathrm{wt} \% \mathrm{CaCO}_{3}$.

good sphericity, and particle diameter distribution is also uniform.

Fig. 8 shows the SEM images of calcium alginate particles after being freeze-dried. Fig. 8(a) and (b) show calcium alginate microparticles without $\mathrm{CaCO}_{3}$; the internal structure of the particles is irregular. The interspace inside the particles is large and easy to break. Fig. 8(c) and (d) show calcium alginate microparticles with $\mathrm{CaCO}_{3}$; the $\mathrm{CaCO}_{3}$ microparticles are uniformly distributed inside the calcium alginate particles and around the surface. Compared with calcium alginate microparticles without $\mathrm{CaCO}_{3}$, calcium alginate microparticles with $\mathrm{CaCO}_{3}$ had uniform internal pore structures. These results are consistent with previous reports. So, the nozzle is applicable for preparing calcium alginate microparticles with other substances.

\section{Discussion}

Novel nozzles are presented for producing calcium alginate microparticles. They use gas as continuous phase and sodium alginate as dispersed phase. The dispersed phase outlet is coaxial with an annular continuous phase outlet. Most traditional methods can only create two-dimensional plane channels, and air flow channels can only be symmetrically designed, ${ }^{7,8}$ but not coaxial with a dispersed phase channel. Gas flow distribution with a coaxial structure is more uniform than that of a symmetrical gas outlet. $^{34-36} 3 \mathrm{D}$ printing can print three-dimensional channels, so that the dispersed phase channel and the annular gas flow channel can be printed concentrically through structural optimization, achieving uniform distribution of gas around the droplets. Therefore, the prepared particles have a low $\mathrm{CV}$ value.
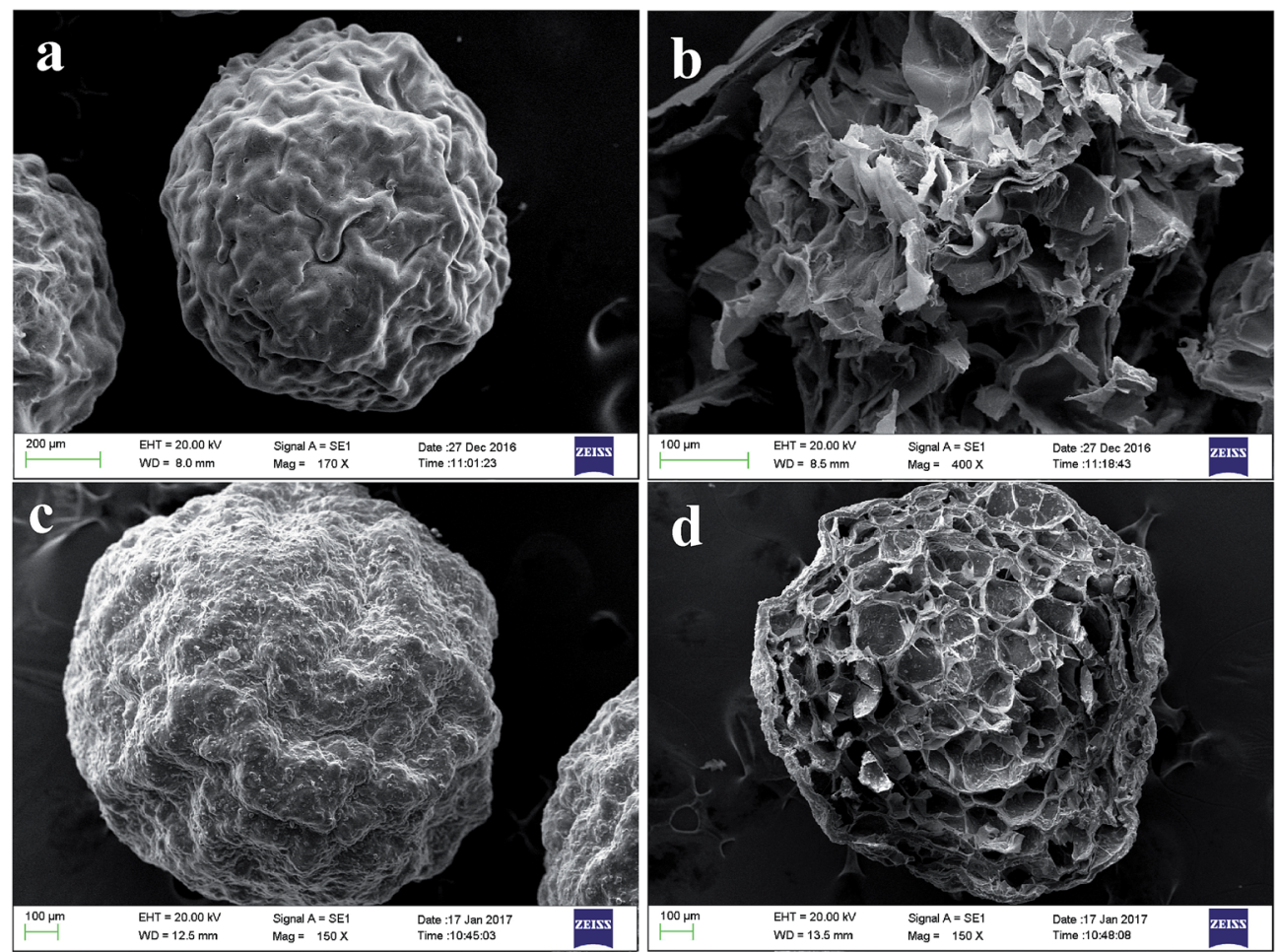

Fig. 8 SEM images of calcium alginate particles. (a) Calcium alginate particle surface. (b) Calcium alginate particle cross-section. (c) $\mathrm{CaCO}_{3}$ calcium alginate particle surface. (d) $\mathrm{CaCO}_{3}$ calcium alginate particle cross-section. 
The nozzles we used were printed one at a time by $3 \mathrm{D}$ printing technology. The printing time of our nozzle was less than 2 hours and the resin cost was no more than $\$ 5 .{ }^{37}$ Besides, dimensional accuracy could be easily guaranteed and repeatable. The new structure kept the two channels coaxial. As for the silicon surface micromachining method, ${ }^{7}$ its dimensional accuracy is favorable but the process needs a professional and has a high cost. For glass capillary ${ }^{8}$ assembling, needles welding, ${ }^{34}$ and tube ${ }^{28,35}$ assembling methods, the materials are cheap but the processes are quite labor consuming. Most importantly, it's hard to guarantee accuracy within a range of tens of microns by conventional manual methods. It's also difficult to guarantee that a continuous phase channel and dispersed phase channel are coaxial. This is key to the good performance of nozzles we want.

SA solution was sheared into droplets by air and directly dripped into $\mathrm{CaCl}_{2}$ solution by the nozzles method. The preparation process is simple and without any additives, so that it can prepare clean droplets with low cost. For liquid-liquid twophase shear methods, the surfactant and oil must be added. Because of its novel structure, the nozzle could prepare calcium alginate microparticles containing $15 \mathrm{wt} \% \mathrm{CaCO}_{3}$ powder without blocking. However, when using traditional microfluidic preparation methods the internal flow path is always long, resulting in a limitation of $\mathrm{CaCO}_{3}$ powder or SA solution concentration. The liquid-liquid shear method is usually suited to prepare sodium alginate at a concentration of less than $2 \mathrm{wt} \% .^{30,31}$

Microparticles prepared by the air-blast nozzle were uniform and had a wide diameter distribution. Diameters of microparticles could be precisely controlled by changing inlet air pressure. The $300 \mu \mathrm{m}$ nozzle can produce particles in a diameter range from $2100 \mu \mathrm{m}$ to $380 \mu \mathrm{m}$ with a CV less than $5.32 \%$. Compared to T-type, focusing microfluidics, and other methods, particles prepared by this nozzle have a significantly larger range of particle sizes. Without changing the nozzle, only changing the inlet air pressure can meet most particles production needs. Besides, when using the liquid-liquid twophase shear method to prepare microparticles, the general flow rate can only be tens of $\mu \mathrm{L} \min ^{-1}$ (ref. 38) but the flow rate of our $300 \mu \mathrm{m}$ diameter nozzle can reach to $800 \mu \mathrm{L} \mathrm{min}^{-1}$.

\section{Conclusions}

In this study, we developed an air-blast microfluidic droplet preparation nozzle using 3D printing, which can be directly connected to Teflon pipes, $3 \mathrm{~mm}$ plastic trachea, and be used immediately after assembling. The process of $3 \mathrm{D}$ printing is efficient, low cost, and simple. Most importantly, it provides reliable accuracy. The coaxial design of the continuous phase channel outlet and dispersed phase channel outlet can remain centered to avoid deformation. This provides a uniform gas flow distribution. The length of the microchannel is short, which is smaller than other microfluidic chips. It is not easy to block and can be used to handle a high viscosity solution and solutions containing solid particles.
The nozzle uses gas to cut the liquid to produce droplets without adding surfactant and continuous phase or other impurities, which can thus produce clean functional particles. By controlling gas pressure, the $300 \mu \mathrm{m}$ nozzle can prepare particles with large sizes ranging from $380 \mu \mathrm{m}$ to $2100 \mu \mathrm{m}$, whose CV values are less than $5.32 \%$. The smaller the nozzle outlet diameter is, the smaller the required inlet gas pressure and CV values are. All the parameters measured in these experiments prove that the particles prepared by this nozzle are adjustable, controllable, and uniform.

\section{Conflicts of interest}

There are no conflicts to declare.

\section{Acknowledgements}

Work supported by the research grant (No. 16DZ2260600) from Science and Technology Commission of Shanghai Municipality, and the Fundamental Research Funds for the Central Universities" (222201717012, 222201718005).

\section{References}

1 P. S. Dittrich and A. Manz, Nat. Rev. Drug Discovery, 2006, 5, 210.

2 A. Tourovskaia, X. Figueroamasot and A. Folch, Lab Chip, 2005, 5, 14-19.

3 T. Nisisako, Curr. Opin. Colloid Interface Sci., 2016, 25, 1-12.

4 Y. He, Y. Wu, J. Z. Fu, Q. Gao and J. J. Qiu, RSC Adv., 2015, 5, $78109-78127$.

5 J. L. Madrigal, R. S. Stilhano, C. Siltanen, K. Tanaka, S. N. Rezvani, R. P. Morgan, A. Revzin, S. W. Han and E. A. Silva, J. Mater. Chem. B, 2016, 4, 6989-6999.

6 J. H. Cui, J. S. Goh, S. Y. Park, P. H. Kim and B. J. Le, Drug Dev. Ind. Pharm., 2001, 27, 309.

7 S. Sugiura, T. Oda, Y. Aoyagi, R. Matsuo, T. Enomoto, K. Matsumoto, T. Nakamura, M. Satake, A. Ochiai, N. Ohkohchi and M. Nakajima, Biomed. Microdevices, 2007, 9, 91-99.

8 H. P. Wang, N. Ding, Y. L. Zhou, Y. J. Chen and C. C. Zhang, Acta Polym. Sin., 2015, 11, 1336-1343.

9 X. M. Yang, Z. W. Zhong, E. Q. Li, Z. H. Wang, W. Xu, S. T. Thoroddsen and X. X. Zhang, Soft Matter, 2013, 9, 11113-11119.

10 E. Q. Li, J. M. Zhang and S. T. Thoroddsen, J. Micromech. Microeng., 2014, 24, 563-590.

11 H. N. Chan, Y. Chen, Y. Shu, Y. Chen, Q. Tian and H. Wu, Microfluid. Nanofluid., 2015, 19, 9-18.

12 Y. Q. Fan, M. Wang and Y. J. Zhang, Chin. J. Anal. Chem., 2016, 44, 551-561.

13 Y. He, Y. Wu, J. Z. Fu, Q. Gao and J. J. Qiu, Electroanalysis, 2016, 28, 1658-1678.

14 A. A. Yazdi, A. Popma, W. Wong, T. Nguyen, Y. Pan and J. Xu, Microfluid. Nanofluid., 2016, 20, 50.

15 J. M. Zhang, A. A. Aguirrepablo, E. Q. Li and S. T. Thoroddsen, RSC Adv., 2016, 6, 2793-2799. 
16 J. M. Zhang, A. Aguirrepablo, E. Q. Li, U. Buttner and S. T. Thoroddsen, RSC Adv., 2016, 6, 81120-81129.

17 K. C. Bhargava, B. Thompson and N. Malmstadt, Proc. Natl. Acad. Sci. U. S. A., 2014, 111(42), 15013-15018.

18 A. K. Au, W. Lee and A. Folch, Lab Chip, 2014, 14, 1294-1301.

19 G. Comina, A. Suska and D. Filippini, Lab Chip, 2014, 14, 424-430.

20 T. Femmer, A. Jans, R. Eswein, N. Anwar, M. Moeller, M. Wessling and A. J. Kuehne, ACS Appl. Mater. Interfaces, 2015, 7, 12635-12638.

21 H. Wang, S. Masood, P. Iovenitti and E. C. Harvey, International Symposium on Microelectronics \& Mems, 2001, vol. 4590, pp. 213-220.

22 A. Bonyár, H. Sántha, B. Ring and M. A. Varga, Procedia Eng., 2010, 5, 291-294.

23 A. I. Shallan, P. Smejkal, M. Corban, R. M. Guijt and M. C. Breadmore, Anal. Chem., 2014, 86, 3124.

24 T. E. Faber, Fluid Dynamics for Physicists, Cambridge University Press, 1995.

25 M. Workamp, S. Alaie and J. A. Dijksman, Rev. Sci. Instrum., 2016, 87(12), 125113.

26 I. Horiguchi and Y. Sakai, J. Visualized Exp., 2015, (101), e52835.

27 Y. Mahdi, K. Daoud and L. Tadrist, C. R. Mec., 2017, 345(4), 259-270.
28 A. L. R. Costa, A. Gomes, F. Y. Ushikubo and R. L. Cunha, J. Food Eng., 2017, 209, 18-25.

29 Z. Dong, H. Xu, Z. S. Bai, H. Z. Wang, L. Zhang, X. J. Luo, Z. Y. Tang, R. Luque and J. Xuan, $R S C A d v$., 2015, 5, $78352-78361$.

30 Y. Hu, Q. Wang, J. Wang, J. Zhu, H. Wang and Y. Yang, Biomicrofluidics, 2012, 6, 26502-265029.

31 Q. Wang, S. Liu, H. Wang, J. Zhu and Y. Yang, Colloids Surf., A, 2015, 482, 371-377.

32 S. W. Choi, S. K. Moon, J. Y. Chu, H. W. Lee, T. J. Park and J. H. Kim, Macromol. Res., 2012, 20, 447-452.

33 F. Davarc1, D. Turan, B. Ozcelik and D. Poncelet, Food Hydrocolloids, 2017, 62, 119-127.

34 A. Sergeeva, N. Feoktistova, V. Prokopovic, D. Gorin and D. Volodkin, Adv. Mater. Interfaces, 2016, 2, 1500386.

35 C. Wang, H. Liu, Q. Gao, X. Liu and Z. Tong, Carbohydr. Polym., 2008, 71, 476-480.

36 Y. K. Lee, S. J. Park, S. Cho, Y. Lee, S. Y. Ko, J. O. Park and S. Park, 13th International Conference on Control, Automation and Systems, Gwangju, Korea, 2013, pp. 15081512.

37 A. Waldbaur, H. Rapp, K. Lange and B. E. Rapp, Anal. Methods, 2011, 3(12), 2681-2716.

38 T. D. Dang and S. W. Joo, Colloids Surf., B, 2013, 102, 766771. 